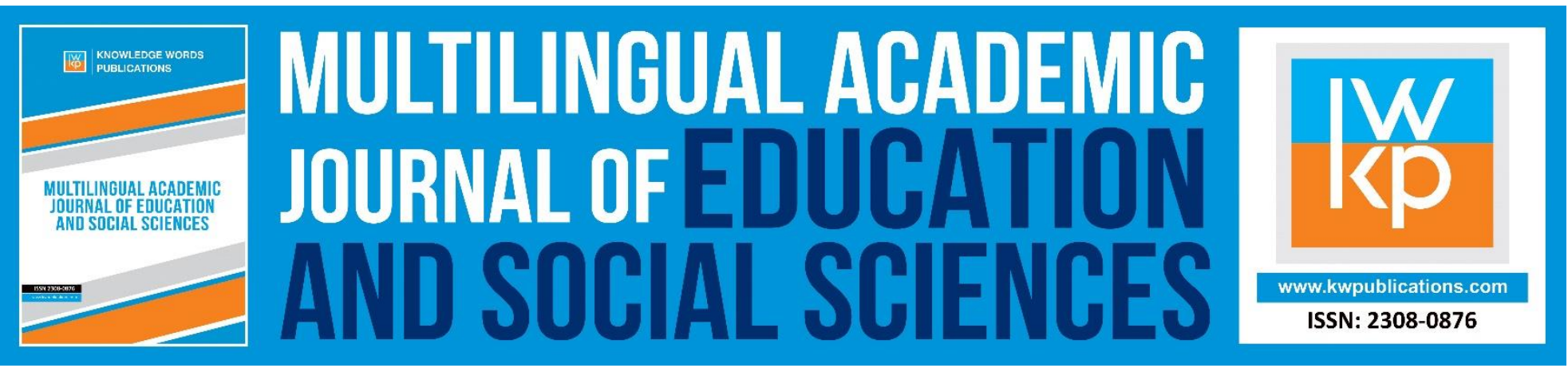

\title{
The Effect of Orientation and Mobility Curriculum on the Academic Achievement of Visually Impaired Children among Public and Private Institutions of Lahore
}

\author{
Shazia Malik \& Umi Kalthom Abdul Manaf
}

To Link this Article: http://dx.doi.org/10.46886/MAJESS/v6-i1/4501

DOI: 10.46886/MAJESS/v6-i1/4501

Received: 02 February 2018, Revised: 05 May 2018, Accepted: 10 June 2018

Published Online: 29 July 2018

In-Text Citation: (Malik \& Manaf, 2018)

To Cite this Article: Malik, S. \& Manaf, U.K. (2018). The Effect of Orientation and Mobility Curriculum on the Academic Achievement of Visually Impaired Children among Public and Private Institutions of Lahore. Multilingual Academic Journal of Education and Social Sciences, 6(1), 12-21.

Copyright: (C) The Authors 2018

Published by Knowledge Words Publications (www.kwpublications.com)

This article is published under the Creative Commons Attribution (CC BY 4.0) license. Anyone may reproduce, distribute, translate and create derivative works of this article (for both commercial and non-commercial purposes), subject to full attribution to the original publication and authors. The full terms of this license may be seen

at: http://creativecommons.org/licences/by/4.0/legalcode

Vol. 6, No. 1, 2018, Pg. 12 - 21

https://kwpublications.com/journals/journaldetail/MAJESS

JOURNAL HOMEPAGE

Full Terms \& Conditions of access and use can be found at https://kwpublications.com/pages/detail/publication-ethics 


\title{
The Effect of Orientation and Mobility Curriculum on the Academic Achievement of Visually Impaired Children among Public and Private Institutions of Lahore
}

\section{Shazia Malik \& Umi Kalthom Abdul Manaf}

Faculty of Educational studies, University Putra Malaysia

\begin{abstract}
The present study endeavors to assess the impact of orientation and mobility curriculum associated with special education for visually impaired students in Pakistan. This study aims to scrutinize whether the present special education curriculum for visually impaired children would be considered effective without the involvement of orientation and mobility curriculum or not. A questionnaire consisting of 10 items was developed for data collection. The sample of the study consisted of 110 visually impaired students among public and private visually impaired institutes in Lahore, Pakistan, according to the table of (Kerjice \& Morgan, 1970). Among the participants, 67 were boys and 43 were girls, age ranged from 5 to 20 years, and they were from starters to $6^{\text {th }}$ grade levels. The present study approves that the visually impaired students can be promoted from the certain nurturing situation, when they have least educational or psychological hindrances. The study indicates that the visually impaired students can actively perform their essential part in presenting excellent educational achievement based on orientation and mobility curriculum for the visually impaired children., However, some hazards incidents have depressed the whole contribution of this relegated class of students from their basic opportunity of Education.
\end{abstract}

Keywords: Curriculum, Visually Impaired Students, Orientation, Academic Achievement.

\section{Introduction}

Visually impaired students should be equipped with essential, needed and technology based skills for empowering them to apply easy and technology bases approaches for getting desired information during their study and daily practices. Moreover, it is extremely significant for visually impaired students, including those who have related infirmities, that require orientation 
MULTILINGUAL ACADEMIC JOURNAL OF EDUCATION AND SOCIAL SCIENCES

Vol. 6 No. 1, 2018, E-ISSN: 2308-0876 @ 2018 KWP

and mobility (O\&M) amenities, to get appropriate coaching in orientation and mobility as soon as conceivable (Lagrow, 1994).

Offering required orientation and mobility services to visually impaired students at the suitable time can enhance the probability that they can take part evocatively in a range of sectors. It can be helpful in their teaching and training, including nonacademic, academic, and extramural activities and practices. Once these students are no longer in their academic institutions, their exercise and practice of attaining orientation and mobility expertise must increase their efficiency of moving around self-sufficiently in a range of academic, professional, and communal settings significantly. These assistances should also develop the capability of visually impaired children for getting jobs, retaining their professions, and taking part more completely in community and family life (Ahmed, Khan, \& Nasem, 2011).

A visually impaired student's requirement for orientation and mobility facilities and the apt technique or approaches are essential for consideration. The attainment of mandatory skills must be measured. It would be proficient commonly via an assessment of motor capabilities, visualization and expansive position and that must be conducted as early as possible (Farooq, 2012). Fazzi and Petersmey (2001), stated that this (Orientation and Mobility) is especially significant since respective associations and parents representing the comforts and welfares of visually impaired children have reported that these children are not acquiring suitable orientation and mobility services and those applicable evaluations of their necessities for these facilities are not being steered. In order to execute the above matter, the consequences of all valuations managed to the child, including those directed to control the child's academic demands subsequent to one or more debility other than visual impairment, must be measured as the student's IEP is advanced (Fazzi \& Petersmey, 2001).

The target of this examination is to evaluate the effect of orientation and mobility curriculum with regard to the special education for visually impaired children across the private and public institutions of Lahore. Orientation and mobility curriculum offers a dynamic procedure to visually impaired children, who in any way holds a disability to learn something new in his/her academic sphere. This is a determined reality that the condition of Pakistan is one of those countries, which do possess a defined academic infrastructure for visually impaired students. However, it is not completely advanced yet for blind or visually impaired students. Through orientation and mobility curriculum, the education and applied learning of visually impaired children can be a significant article on the education and if this aspect is ignored by the particular management and control, it will be a very biased and harsh action (Khan \& Behlol, 2014).

\section{Objectives of the Study \\ This Study Aims}

1. To assess the impact of orientation and mobility curriculum associated with special education for visually impaired students in Pakistan.

2. To identify whether the present special education curriculum for visually impaired children would be considered effective operative and functional without the involvement of orientation and mobility curriculum or not? 
MULTILINGUAL ACADEMIC JOURNAL OF EDUCATION AND SOCIAL SCIENCES

Vol. 6 No. 1, 2018, E-ISSN: 2308-0876 @ 2018 KWP

\section{Literature Review}

According to Fatema (2013), this fact is a dilemma for the visually impaired children who are living in corners of Pakistan. The incapacity changes the mode, visually disabled children get information regarding the world around them and restricts scenarios to get educated by observation of visual orientation and mobility components in the special education curriculum. It is proven that special education is a system of learning enclosed by the control of system and defined mechanism, predominantly delineated to access the academic demands of visually impaired children (Fatema, 2013).

In the book, "Orientation and Mobility: Techniques for Independence", Lagrow has highlighted the status of special education for all those students who by any means are suffering from any sort of physical weakness (Lagrow, 1994). It is a fact that special education is the part of recognized system of learning and it should be given equal significance. But the situation of special education for the children with visually impaired problems is quite dreadful in big cities of Pakistan (Ali, 2008). The term special education means that in learning. With regard to these special students, the same exceptional services like orientation and mobility curriculum accompanied by special behavior and preliminary tactics are implemented to facilitate the visually impaired children to feel fitting under the banner of overall prescribed curriculum (Lagrow, 1994).

In Pakistan, the condition of visually impaired children is fairly stern regarding the present curriculum of the education with reference to orientation and mobility. Specifically, the syllabus is planned to educate visually impaired students. In this concern, an operational feature of this curriculum that is correspondingly significant for the special education of the visually impaired children is an orientation and mobility curriculum (Stuen, et al., 2000).

\section{Orientation and Mobility Curriculum}

Orientation or mobility curriculum is an acknowledged procedure in which both learners and instructors aim to determine a jointly friendly policy of educating visually impaired students. In this regard, the student-teacher interaction can be the necessity of sustenance to cope with their individual inadequacies as well as with the demands of the visually impaired student. It is rather disheartening to highlight that the development of orientation and mobility curriculum is typically ignored by the contemporary Pakistani program of special education outlined for visually impaired students. The orientation should be an insistent process, in which the corresponding teachers and educators can learn to recognize the visually impaired student as an unusual individual (Hill \& Ponder, 1976).

Additionally, it is also a reality that in the cultured zone of the Pakistani community, the demand for special education is perceived as a righteous cause of coaching, reintegration and concerned support policies for all the students with special needs, particularly children with visual deficiency. In this concern, the contemporary special educational system reveals some merits and certain failings too (Stuen, et al., 2000).

\section{Special Education for Visually Impaired in Pakistan}

The mechanism of special education in Pakistan for visually impaired children has been blamed for strengthening and supporting the current instable communal planning since quite a few visually impaired learners from the civic sector academic institutions move up the position of 
MULTILINGUAL ACADEMIC JOURNAL OF EDUCATION AND SOCIAL SCIENCES

Vol. 6 No. 1, 2018, E-ISSN: 2308-0876 @ 2018 KWP

social mobility. In this region, special education is supposed to be a regional or regional duty and has been reorganized to constituency levels in accordance with the current devolution strategy. Presently, there are two educational mechanisms that are currently present for the students with any corporeal incapacity, including visual impairment; regular and normal education and special schooling (Yasmin, Minto, \& Khan, 2010).

The special instruction system covers both institutional and residential aid. Furthermore, the special training and learning of children with sight deficiency is presented through a linkage of more than sixty (60) institutes for the students with visual impairment managed by the regional and central administrations, and several NGOs. Throughout the preceding years, one of the Pakistani provinces, the Punjab, has initiated to launch more than one hundred institutes, especially assigned to the students with sight issues (Ahmed, Khan, \& Nasem, 2011).

In special education for the visually impaired children, the importance and role of orientation and mobility curriculum cannot be ignored. The idea of comprehensive and practical learning based on orientation and mobility aid for visually impaired students, is quite new in Pakistan. Further, the students with the visual issue can feel the effect of orientation and mobility curriculum in their routine life (Fatema, 2013)

The present study is based on the theoretical framework of "Orientation \& Mobility Model", to fill the literature gap in Pakistani context, where the curriculum for visually impaired students is not quite different from normal sighted students. It is a concept that pursues to explain the orientation and mobility practice in the sphere of special education with reference to visually impaired children. This model or theory presents groundwork to the theme in the debate. The Orientation \& Mobility Model discusses the tangible communication and interaction mechanism to instruct orientation and mobility in the sector of mobility education. This theory or model instructs and guides the ways, how visually impaired children can be mobile and practical in their routine lives (Fowler, 1997). The orientation and mobility model of COMS/OMA (Certified Orientation Mobility Specialist) and (Orientation and Mobility Assistant) has been implemented for the research work. According to this model COMS and OMA perform as a unit with a view to present quality services to the visually impaired children. With a view to assist launch a quality OMA policy, it is suggested that new OMAs be administered by COMS who are equipped with minimum two years of educational experience. If an administering COMS leaves a continuing OMA plan, the COMS recruited to substitute the supervisor require not to have previous teaching experience; however, it should get the competencies demanded for oversee OMAs (Hill \& Ponder, 1976). This model fills the literature gap especially for Pakistan context, where the scholar has chosen the visually impaired respondents from Lahore city, to make them more independent through the usage of this model as essential part of their curriculum for both the learners and the instructors. As there are some other negatively affecting factors for instance lack of resources and funds, which are still in the form of controversial debate.

\section{Methodology}

This research is descriptive and quantitative in nature. A questionnaire was developed by the researcher, using content validity. A sample of 110 visually impaired children from public and private institutions of Lahore city in Pakistan was selected as convenient sampling. This population of Lahore is selected to see the effect of orientation and mobility as a compulsory object of the curriculum for visually impaired students. The sample size was determined 
MULTILINGUAL ACADEMIC JOURNAL OF EDUCATION AND SOCIAL SCIENCES

Vol. 6 No. 1, 2018, E-ISSN: 2308-0876 2018 KWP

according to the sampling table of Kerjice \& Morgan (1970) as $(n=110)$ from public and private institutes of visually impaired children Lahore city, Pakistan. 110 boys and girls, aged 05-20 years were selected for age, gender and educational level. Descriptive statistical techniques such as means, frequencies and percentages were used to analyze the data. Data was analyzed through SPSS (Statistical Packages for Social Sciences).

Data Analysis \& Findings

Reliability Analysis

\begin{tabular}{|c|c|}
\hline Cronbach's Alpha & N of Items \\
\hline 0.711 & 10 \\
\hline
\end{tabular}

The Cronbach Alpha for the questionnaire was 0.7 , which means a good scale for reliability. The reliability scale for the questionnaire used as the instrument for the current research study was 0.711 for 13 items-scales. The reliability was on a satisfactory level of the research instrument, hence, endorsing that the response rate collected through this instrument would carry a high validity.

\section{Frequency Analysis}

After the data was collected, it is analyzed by calculating the frequency scores.

Table 1. Frequencies showing the age of students

\begin{tabular}{cccc}
\hline & & Frequency & Percent \\
\hline Valid & $0-5$ & 20 & 10.0 \\
& $6-10$ & 40 & 52.0 \\
& $10-15$ & 29 & 26.0 \\
& $15-20$ & 21 & 12.0 \\
& Total & 110 & 100.0 \\
\hline
\end{tabular}

This table shows that 20 students with age (in years) of 0-5, 40 among 6-10, 29 among 10-15, and 21 among 15-20.

Table 2. Frequencies showing the gender of students

\begin{tabular}{cccc}
\hline & & Frequency & Percent \\
\hline Valid & Male & 67 & 76.0 \\
& Female & 43 & 24.0 \\
& Total & 110 & 100.0 \\
\hline
\end{tabular}

This table shows that 67 male and 43 female students participated. 
MULTILINGUAL ACADEMIC JOURNAL OF EDUCATION AND SOCIAL SCIENCES

Vol. 6 No. 1, 2018, E-ISSN: 2308-0876 @ 2018 KWP

Table 3. Frequencies showing the education level of students

\begin{tabular}{llrr}
\hline & & Frequency & Percent \\
\hline Valid & Starters & 31 & 24.0 \\
& Grade 1-3 & 44 & 42.0 \\
& Grade 4-6 & 35 & 34.0 \\
& Total & 110 & 100.0
\end{tabular}

This table shows students were 31 in the starter grade, 44 for grade $1-3$, and 35 for the grades of 4-6.

Descriptive Analysis

\begin{tabular}{lccc}
\hline & N & Mean & Std. Deviation \\
\hline Active members & 110 & 1.9600 & 1.00934 \\
$\begin{array}{l}\text { Students feel change after } \\
\text { application }\end{array}$ & 110 & 2.7800 & 1.14802 \\
$\begin{array}{l}\text { Special school suits the children } \\
\text { Educators plan their teachings }\end{array}$ & 110 & 2.6400 & 1.30556 \\
$\begin{array}{l}\text { Consistent with the requirement of } \\
\text { the learning }\end{array}$ & 110 & 3.5400 & 1.28110 \\
$\begin{array}{l}\text { Educators professionally dexterous } \\
\text { Do the trainers practice }\end{array}$ & 110 & 3.9200 & 1.08496 \\
$\begin{array}{l}\text { communication } \\
\text { Instructors guide to practically }\end{array}$ & 110 & 3.7000 & 1.28174 \\
$\begin{array}{l}\text { perform } \\
\text { Children experience any change in }\end{array}$ & 110 & 4.0600 & 1.16776 \\
$\begin{array}{l}\text { academic } \\
\text { Students and parents satisfied with } \\
\text { the practical approach }\end{array}$ & 110 & 2.9800 & 1.31692 \\
\begin{tabular}{l} 
Valid N (list wise) \\
\hline
\end{tabular} & 110 & & 1.26749 \\
\hline
\end{tabular}

\section{Results of the Study}

Virtually $85 \%$ of the partakers in the interviewing session approved that learners with visual issues have developed a great sense of an active and practical approach while being learnt by orientation and mobility curriculum. $65 \%$ agreed, whereas $15 \%$ were in sturdy agreement in reaction to the item-scale inquired. Among the participants, $65 \%$ visually impaired students had the view that with the help of orientation and mobility curriculum, they have been able to grasp the most educational stuff with clarity and comprehensiveness. The impact of orientation and mobility technique of education has influenced a lot on their learning speed and overall education and academic performance.

This is the preview of standard communal attitude as in Pakistani society, there are only quite a few job openings for special candidates particularly those who have sight issues. Through questioning, it has been observed that most of the students felt quite tricky and intricate to follow the instructive measures of orientation and mobility curriculum, but later on through 
MULTILINGUAL ACADEMIC JOURNAL OF EDUCATION AND SOCIAL SCIENCES

Vol. 6 No. 1, 2018, E-ISSN: 2308-0876 @ 2018 KWP

constant practice and substantial application of those techniques, they actually realized its effect and impact on their educational performance and academic accomplishments.

About 50 percent visually impaired students revealed that owing to their visual incapacity, they used to suffer inferiority complex among their sighted siblings, but with the practical and functional approach of orientation and mobility measures, the routine life became more easy and practical for them and they felt a considerable change in their educational sphere of life. 30\% visually impaired students asserted that it took them a lot of time to learn and get adjusted in accordance with the orientation and mobility curriculum and resultantly. They felt delayed to present substantial outcomes in the field of academic accomplishment.

It has been observed that more than $85 \%$ parents, teachers and concerned students experienced that the practice of orientation and mobility curriculum in special schools is the best for the visually impaired children since there are assured provisions in special institutes for their incapacity. $40 \%$ visually impaired children agreed with the statement that their respective instructors plan and arrange their academic lessons according to the demands of their infirmity in the light of orientation and mobility course.

$15 \%$ of the children still responded that they feel difficulty while academically performing according to orientation and mobility curriculum. In this case mainstream of the students around $55 \%$ did agree to the planned lessons arranged by their instructors. On the contrary, while responding to the other question, $50 \%$ of the parents and $70 \%$ of the instructors discovered that the existing curriculum is quite consistent with the capabilities of all the children, though it demands some enhancements. Further, $90 \%$ educators declared that they were fairly expert in handling children with visual weakening. In contrast, $70 \%$ visually impaired children replied in positive sanctioning the declarations of teachers and parents.

$90 \%$ instructors shared that they practiced a range of orientation and mobility techniques to interconnect with the visually impaired students with a view to make the lecture and lesson comprehensive. Almost $50 \%$ parents responded that their visually weakened children are instructed how to perform at home with this infirmity and by doing so, they have proved themselves to thrive in the academic field as well. $80 \%$ of the young learners declared that they did not experience issues while noting down the notes and moving around in the class and each time, the educators helped them when they were confronted with any problem.

$52 \%$ of the visually impaired children asserted that there should be more practical transformation in the current structure of orientation and mobility curriculum. While answering concerned questions as mentioned about the impact and influence of the orientation and mobility curriculum in the special education; almost every student, teacher and parent ascertained with fluctuated ratio that the effect of orientation and mobility curriculum can be experienced on the overall academic achievement of the visually impaired children.

\section{Discussion}

The main objectives of this research were to assess the impact of orientation and mobility curriculum associated with special education for visually impaired students in Pakistan. With this concern in mind, it can be suggested that visually impaired students can benefit from the nurturing condition, when they are free from attitudinal and psychological obstacles and socioeconomic hazards (Asch, 1989). This reality cannot be denied; though there are numerous educational institutes that play a pivotal role in providing professional education to the students 
MULTILINGUAL ACADEMIC JOURNAL OF EDUCATION AND SOCIAL SCIENCES

Vol. 6 No. 1, 2018, E-ISSN: 2308-0876 @ 2018 KWP

with visual impairment. However, the existence of certain threats deprives these special children from their elementary privilege in terms of "Education". These special institutions, with the active participation of expert teachers can play a remarkable role in providing visually impaired students with effective learning involvements.

Moreover, this research was an endeavor to describe the feelings of these students while studying in different educational institutes. Their teachers and parents' perceptions about this concern, were also esteemed to apprehend the phenomenon regarding the issues faced by visually impaired students in special schools in Pakistan. This is widely accepted that the ordinary schools are not restricted to accommodate students with disabilities, especially those with visual impairment, but present their substantial facilities to this community. Furthermore, it requires a resilient political assurance to bring revolutionary changes in the curriculum of special education for visually impaired students especially for orientation and mobility. To this aim, media can play a significant role in supporting and cognizance this move in connection with the glitches faced by students with the disability of visual impairment. Difficulties faced by these students must be carefully observed for the purpose of overcoming the obstacles and improving the situation. Necessary measures should be taken into consideration to revolutionize the current curriculum of the special education (orientation and mobility) in Pakistan for visually impaired students; and optimistic results can be expected for their education and curriculum in special education in Pakistan.

\section{Conclusion}

The main target of this study was to examine and to identify the effect of orientation and mobility curriculum of the academic failure of the visually impaired children under the banner of the existing instructive curriculum. With this target in deliberation, it has been approved that the visually impaired students can be promoted from the certain nurturing situation, when they have least educational or psychological hindrances and socioeconomic threats. This truth cannot be repudiated; although there are abundant learning institutions which are actively performing their essential part in presenting excellent education based on orientation and mobility curriculum for the visually impaired children. However, some hazards incidents have depressed the whole contribution of this relegated class of students from their basic opportunity of Education. At the same time, it has been observed that through dedicated education started on the mechanism of orientation and mobility curriculum, a noticeable impact on the academic achievement of the visually impaired children are achieved.

\section{References}

Ahmed, M., Khan, A. B., \& Nasem, F. (2011). Policies for Special Persons in Pakistan. Berkeley Journal of Social Sciences, 1 (2), 1-11.

Ali, S. S. (2008). 6 Disability, human rights and redistributive justice. Disabled People and the Right to Life, 110.

Farooq, M. (2012). Problems faced by Students with Special Needs in Ordinary Pakistani Schools. Journal of Quality and Technology Management, 8 (1), 13-27.

Fatema, N. (2013). Visually impaired: Push towards independence. (K. Siddiqi, Ed.) The Express Tribune. 
Fazzi, D. L., \& Petersmey, B. A. (2001). Imagining the Possibilities: Creative Approaches to Orientation and Mobility Instruction for Persons Who Are Visually Impaired. New York, United States: AFB Press.

Hill, E. W., \& Ponder, P. (1976). Orientation and Mobility Techniques. New York, United States: Amer Foundation for the Blind.

Khan, I. K., \& Behlol, M. G. (2014, June). Inclusive Education at Primary Level: Reality or Phantasm. Journal of Education and Educational Development, 1(1).

Mazurek, K., \& Winzer, M. A. (1994). Comparative Studies in Special Education (1 Ed.). Washington, D.C., United States: Gallaudet University Press.

Salisbury, R. (2007). Teaching Pupils with Visual Impairment (1 Ed.). London, United Kingdom: David Fulton Publishers.

Stuen, C., Arditi, A., Horowitz, A., Lang, M. A., Rosenthal, B., \& Seidman, K. (2000). Vision Rehabilitation (1 Ed.). Boca Raton, Florida, United States: CRC Press.

Wiener, W. R., Welsh, R. L., \& Blasch, B. B. (2010). Foundations of Orientation and Mobility: Instructional Strategies and Practical Applications (3 Ed.). New York, United States: AFB Press.

Yasmin, S., Minto, H., \& Khan, N. U. (2010). Policy and Practice in the Educational Inclusion of Children and Young People with Visual Impairment in Sri Lanka and Pakistan. The Educator, 22(2), 17-22. 